\title{
Fabrication, mechanical, thermal, and electrical characterization of epoxy/silica composites for high-voltage insulation
}

DOI 10.1515/secm-2015-0445

Received October 27, 2015; accepted February 25, 2017; previously published online April 19, 2017

\begin{abstract}
For improved performance of epoxy, its composites were studied for high-voltage insulation. Epoxy composites may offer several advantages over neat epoxy and ceramic materials. We fabricated nano- and microepoxy/silica composites with $5 \mathrm{wt} \%$ nanosilica and $20 \mathrm{wt} \%$ microsilica, respectively. The composites and neat epoxy were studied for thermal, mechanical, and electrical properties. A thermogravimetric analyzer was used for analyzing wt\% loss with temperature. Tensile and hardness tests were performed according to DIN 53504/ASTM D412 and DIN 53505/ASTM D2240 standards, respectively. Electrical properties such as dielectric strength and resistivity were tested according to IEC-60243-1 and ASTM D257/IEC 60093 standards, respectively. Neat epoxy, microcomposite, and nanocomposite showed 50\% weight loss at $392^{\circ} \mathrm{C}, 410^{\circ} \mathrm{C}$, and $421^{\circ} \mathrm{C}$, respectively. At $550^{\circ} \mathrm{C}$, nanocomposite remained at $20 \%$ of its initial weight whereas neat epoxy and microcomposite remained at $10 \%$ of their initial weights. Microcomposite and nanocomposite showed tensile strengths of 65.7 Mpa and 69.3 Mpa, respectively. Enhancements of $8 \%$ and $19 \%$ in dielectric strength were recorded for microcomposites and nanocomposites, respectively. Nanosilica greatly improved surface and volume resistivity whereas microsilica showed negligible effect on resistivity.
\end{abstract}

Keywords: dielectric strength; epoxy; high-voltage insulation; nanocomposite; TGA.

\footnotetext{
*Corresponding author: Abraiz Khattak, Department for Management of Science and Technology Development, Ton Duc Thang University, Ho Chi Minh City, Vietnam; Faculty of Electrical \& Electronics Engineering, Ton Duc Thang University, Ho Chi Minh City, Vietnam; and Department of Electrical Engineering, City University of Science and Information Technology (CUSIT), Peshawar, Pakistan, e-mail: abraiz.khattak@tdt.edu.vn Muhammad Amin: Department of Electrical Engineering, Ghulam Ishaq Khan Institute of Engineering Sciences and Technology, Topi, Pakistan

Muhammad Ali: Department of Electrical Engineering, University of Engineering and Technology, Taxila, Pakistan
}

\section{Introduction}

Epoxy was introduced in electrical power systems as firstgeneration polymeric insulators. However, they failed shortly due to problems in design and construction. Not only has the construction of polymeric insulators improved in the last few decades but many new methods have also evolved to increase their aging resistance [1-8]. Many credible works have been achieved on the enhancement of the properties of epoxy, such as developing its blends and composites. Composites introduced a new solution for the improvement of polymers' performance without affecting their composition and preparation techniques [9-14].

The characterization of epoxy composites by using different nanoparticles and microparticles has been reported by several authors. However, the available literature does not converge toward concrete information about the characteristics of epoxy composites for use in high-voltage (HV) insulation. For example, Singha and Thomas [15] worked on the influence of dispersion of thermally reduced graphene oxide in epoxy composite; well dispersed reduced graphene oxides resulted in enhancements of nearly $11^{\circ} \mathrm{C}$ in transition temperature and quasistatic fracture toughness was improved by up to $52 \%$. Tensile and dynamic mechanical properties of hybrid epoxy composites of jute and palm were studied by Iyer et al. [16]; both tensile and dynamic behavior properties were greatly improved in the case of hybrid composite with an oil palm/jute ratio of 1:4. Tanaka [17] studied the mechanical properties of silane-functionalized graphene oxide-based epoxy composites. An increase in storage modulus, glass transition temperature, thermal stability, tensile and flexural properties, and fracture toughness of epoxy/silane-functionalized-graphene oxide composites was recorded. Gardea and Lagoudas [18] reported mechanical and thermal properties of epoxy/expanded graphite nanoplates, they reported increased fracture toughness of up to $60 \%$ and an improvement of $36 \%$ was recorded for the expanded graphite nanoplate/epoxy composite with $2 \mathrm{wt} \%$ loading. Chisholm et al. [19] investigated epoxy/graphite nanocomposites for thermal, permeability, and dielectric properties. 
Improvement in all properties was recorded over neat epoxy. Zhou et al. [20] analyzed the thermal properties of epoxy/nano-SiC and epoxy/nano- $\mathrm{Al}_{2} \mathrm{O}_{3}$ composites. Differential scanning calorimetry was used for analysis. The differential scanning calorimetry curve peak temperature of both composites was reduced by increasing the filler content. The integral procedure decomposition temperature improved from $630^{\circ} \mathrm{C}$ to $853^{\circ} \mathrm{C}$ for epoxy/nano- $\mathrm{Al}_{2} \mathrm{O}_{3}$ composite and $858^{\circ} \mathrm{C}$ for epoxy/nano-SiC composite. The char yield at $800^{\circ} \mathrm{C}$ increased from $14.3 \%$ to $26.2 \%$ for epoxy/nano- $\mathrm{Al}_{2} \mathrm{O}_{3}$ and epoxy/nano-SiC, respectively. Dutta and Tripathy [21] studied epoxy composites filled with carbon nanotubes (CNTs) and spherical particles for toughness and electrical properties. Multi-walled carbon nanotubes (MWCNTs) and spherical particles such as silica were combined for the preparation of epoxy composites, which resulted in a good balance in glass transition temperature, electrical conductivity, stiffness, and strength as well as fracture toughness. Sun et al. [22], evaluated dielectric properties of epoxy nanocomposites with different concentrations of inorganic fillers, e.g. $\mathrm{TiO}_{2}, \mathrm{ZnO}$, and $\mathrm{Al}_{2} \mathrm{O}_{3}$. Permittivity and tan delta were increased with increasing concentration of nanoparticles. Conversely, the AC dielectric strength of microcomposite for the same type of particles was higher in comparison to nanocomposites. Meyer et al. [23] also reported the dielectric properties of nanoparticles, microparticles, and nano/microcomposites of epoxy. Contrasting results were obtained from their work in which nanosilica, which is an inorganic oxide filler, was mentioned as a contributor to the loss of dielectric strength in epoxy. Kong et al. [24] explained that the addition of CNTs to epoxy showed a decrease in electrical and thermal resistivity and Tang et al. [25] reported an increase in mechanical properties with the addition of CNT. Jawaid et al. [26] investigated epoxy/SiC composites with nanoand micro-SiC particles in which the nanocomposites were found to have better thermal and mechanical properties in comparison to neat epoxy. The effect of carbon nanofibers on mechanical properties of epoxy was reported by Wan et al. [27], in which the mechanical properties were significantly improved by the addition of carbon nanofibers.

Epoxy composites have been evaluated for different fillers of both microsizes and nanosizes such as inorganic oxides as well as carbonaceous and metallic fillers [28-36]. However, for HV and outdoor insulation applications, they must be thoroughly prepared and investigated for thermal, mechanical, and electrical characteristics. Among a wide range of nanofillers and microfillers, inorganic oxides have been proven to be the better choice for use in epoxy insulation. Similar to other inorganic fillers, silica is a frequently recommended filler for outdoor insulation, which is suitable for the improvement not only of the electrical properties in polymers but also of the thermal and mechanical properties after adding optimized concentrations and preparing its nanocomposites and microcomposites. It has high electrical and thermal resistivity along with good mechanical characteristics. Thus, it can help in improvements of the required characteristics of epoxy insulators. The thermal, mechanical, and electrical characteristics of silica-based epoxy nanocomposites and microcomposites have not been studied in detail for electrical applications. Some of the limited studies performed in the past have shown contrasting results. For example, the work by $\mathrm{Hu}$ et al. [37] illustrated that with $5 \%$ of the fillers in an epoxy nanocomposite, the ac dielectric strengths of layered silicate and $\mathrm{TiO}_{2}$ fillers are slightly lower than that of unfilled epoxy, whereas with $\mathrm{SiO}_{2}$ fillers, it is elevated. Imai et al. [38] demonstrated that the ac electric strength in nanocomposites was slightly higher than the base epoxy and significantly higher than microcomposites. In polymeric nanocomposites at $5 \mathrm{wt} \%$ loading of nanofillers, the nearest neighbor index value was closer to 1 , representing enhanced particle dispersion. Concentrations higher than 5\% resulted in more agglomerates and poor dispersion, which may lead to a decrease in certain properties. Therefore, many authors consider the concentration of $5 \%$ of nanofillers by weight as an optimum value [39]. The microfiller loading can be as high as 50\% wt. However, at very high loading, few properties are increased whereas thermal and electrical properties are compromised [40]. Therefore, up to $20 \%$ loading of microfiller is widely considered as the maximum limit [35]. Due to the larger specific area of nanosilica in comparison to microsilica; microsilica is required in higher concentrations in comparison to nanosilica for equivalent polymer/ particle interface area [41]. The materials' organic-inorganic interface plays a vital role in the characteristics of polymer/ inorganic-filler composites [42, 43].

Keeping in view the importance of epoxy/silica composites for HV insulation, we prepared microcomposites and nanocomposites and analyzed them for mechanical, electrical, and thermal properties.

\section{Materials and preparations}

\subsection{Materials}

Epoxy was procured from Lanxess Chemicals, Germany. Nanosilica and microsilica were purchased from Degussa, USA and Wuhan Newreach Chemicals, China, respectively. The other constituents were industrial grade products. 


\subsection{Fabrication of samples}

Nanosilica was first dispersed in ethanol solution to avoid sticking among the nanofillers. To obtain a fine dispersion, the solution was kept in an ultrasonic bath for 90 min. After this, silane(3-glycidoxypropyltrimethoxysilane) was added for surface functionalization of the fillers. In the next step, epoxy resin was mixed with the mixture in a high shear mixer with a rotational speed of $3600 \mathrm{rpm}$ for $15 \mathrm{~min}$. The solution was then transferred to an ultrasonic bath. Finally, the ethanol, fillers, and epoxy resin mixture was kept in a vacuum oven at a temperature higher than the boiling point of ethanol. It was kept in the oven for 2 days until all the ethanol had evaporated. The second part of the preparation was executed as follows.

The solution was mixed with the hardener and kept in a mixer with a rotational speed of $7200 \mathrm{rpm}$ for about $20 \mathrm{~min}$. The mixture was then reserved in an ultrasonic bath to prepare the solution for degassing. The solution was then set aside in vacuum at $27 \mathrm{in} \mathrm{Hg}$ until the bubbles were completely removed. The mixture was discharged into molds and kept at room temperature for $24 \mathrm{~h}$ [44]. Subsequently, the samples were postcured in a hot oven for $3 \mathrm{~h}$. A list of the prepared samples is presented in Table 1.

\subsection{Instruments and conditions}

\subsubsection{Mechanical tests}

For the evaluation of tensile properties, the samples were cut into dog bone shapes with dimensions as shown in Figure 1. Values were measured on three specimens of each

Table 1: Prepared epoxy composite samples.

\begin{tabular}{ll}
\hline Filler concentration (wt\%) & Sample code \\
\hline $0 \%$ & NEP (neat epoxy) \\
$20 \%$ Micro & EPMC (epoxy microcomposite) \\
$5 \%$ Nano & EPNC (epoxy nanocomposite) \\
\hline
\end{tabular}

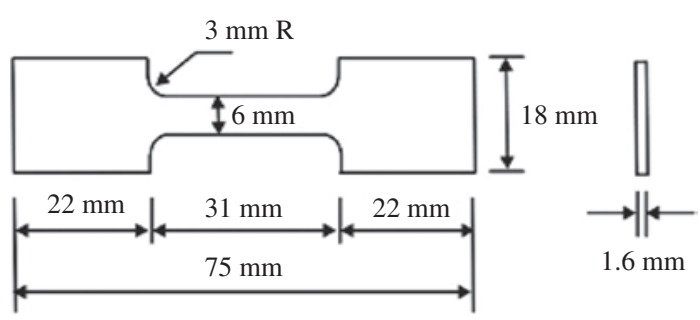

Figure 1: Dog bone sample shape and size. type at a low deformation speed of $100 \mathrm{~mm} / \mathrm{min}$ according to DIN 53504/ASTM D412 standards. Instron (UK) Universal Testing Machine was used for the evaluation of tensile properties. For each formulation, 5-10 samples were tested and average values were reported.

The hardness of each sample was calculated according to DIN 53505/ASTM D2240 standard using Shore-A durometer. Hardness was measured at five different points of each sample and average values were reported.

\subsubsection{Thermal tests}

For the evaluation of thermal properties, a thermogravimetric analyzer (TGA Q50; TA Instruments, USA) was used. Thermograms were obtained under $\mathrm{N}_{2}$ atmosphere at a scanning rate of $10^{\circ} \mathrm{C} / \mathrm{min}$. The tests were performed from $25^{\circ} \mathrm{C}$ to $600^{\circ} \mathrm{C}$.

\subsubsection{Electrical tests}

Alternating voltage was used for the evaluation of dielectric strength. The voltage was increased from $0 \mathrm{~V}$ until the breakdown of samples according to IEC-60243-1 standards. For each sample, a minimum of five values were recorded and average values were reported.

Breakdown tests were carried out on the filled and the unfilled samples to investigate the behavior of the samples containing nanofillers using the setup shown in Figure 2. Ten measurements were recorded for each sample type. Only small differences were observed in the breakdown values of different samples.

For the calculation of surface and volume resistivity, the ASTM D257/IEC 60093 standard was followed. For $60 \mathrm{~s}$, a 4-in. specimen was placed between two electrodes. A voltage was applied and the resistance was measured. Surface or volume resistivity was calculated using resistance and the dimensions of the sample [45].

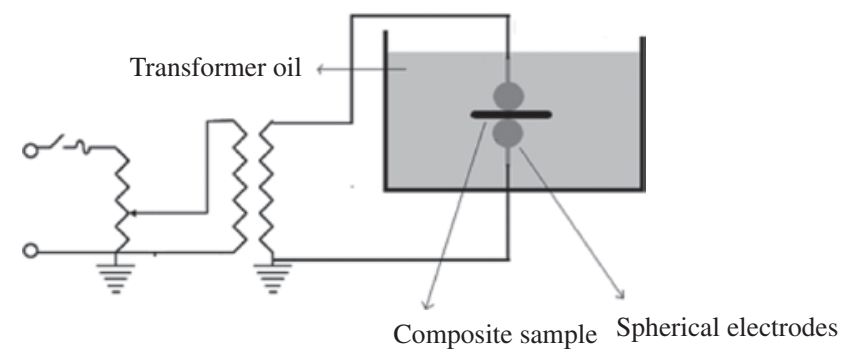

Figure 2: Schematic for breakdown experiment. 


\section{Results and discussion}

\subsection{Mechanical properties}

Significant enhancements in the tensile properties of microcomposites and nanocomposites were recorded. The enhancement was higher in the case of nanocomposites, which may be due to the fine dispersion, high surface area, and abundance of silanol groups of nanosilica. The oxygen atoms on the silica surface resulted in hydrogen bonding in the epoxy, which contributed toward the superior tensile strength in composites. Furthermore, the addition of silica resulted in a reduction of hardness and percentage of elongation. Tensile strength, percentage of elongation and hardness for all samples are given in Figure 3A-C.

For NEP (neat epoxy), tensile strength, elongation, and hardness were $64.2 \mathrm{Mpa}, 110 \%$ and $54 \%$, respectively. For EPMC (microcomposite), $65.7 \mathrm{Mpa}$ tensile strength was observed and an increase of $3.7 \%$ in hardness was recorded. A decrease of $8 \%$ in elongation was recorded in EPMC. Similarly, For EPNC (nanocomposite), the tensile strength increased to $69.3 \mathrm{Mpa}$ and hardness increased to $9.2 \%$. Similar to microcomposites, elongation also decreased in nanocomposites by $12 \%$. The decreasing trend in elongation was due to the stiffness of the overall composites imparted by rigid and inflexible silica. The results also showed that even at $75 \%$ lower concentration than microsilica, nanosilica greatly amends the mechanical properties of epoxy. The reason for this enhanced effect of nanosilica on polymer matrix is its size, in which it interacts at the nano level with polymer bulk. This interaction also lessens the movement of polymer chains, which results in increased hardness.

\subsection{Thermal properties}

To analyze in detail the thermal stability of each formulation, their individual thermograms were obtained and are given in Figure 4A-C. The loss of weight was faster in case of NEP whereas it was observed that the length of the slope of the weight loss curve increased with the addition of silica. At the end of the experiment at $550^{\circ} \mathrm{C}$, the NEP and EPMC lost almost $90 \%$ of their weights whereas EPNC lost almost $80 \%$, which shows evidence of improved thermal stability. Table 2 shows percentage of char yield at $550^{\circ} \mathrm{C}$ and temperatures at $10 \%$ weight loss $\left(T_{10}\right)$ and $50 \%$ weight loss $\left(T_{50}\right)$. It has been observed that the EPNC sample was more stable in comparison to other samples
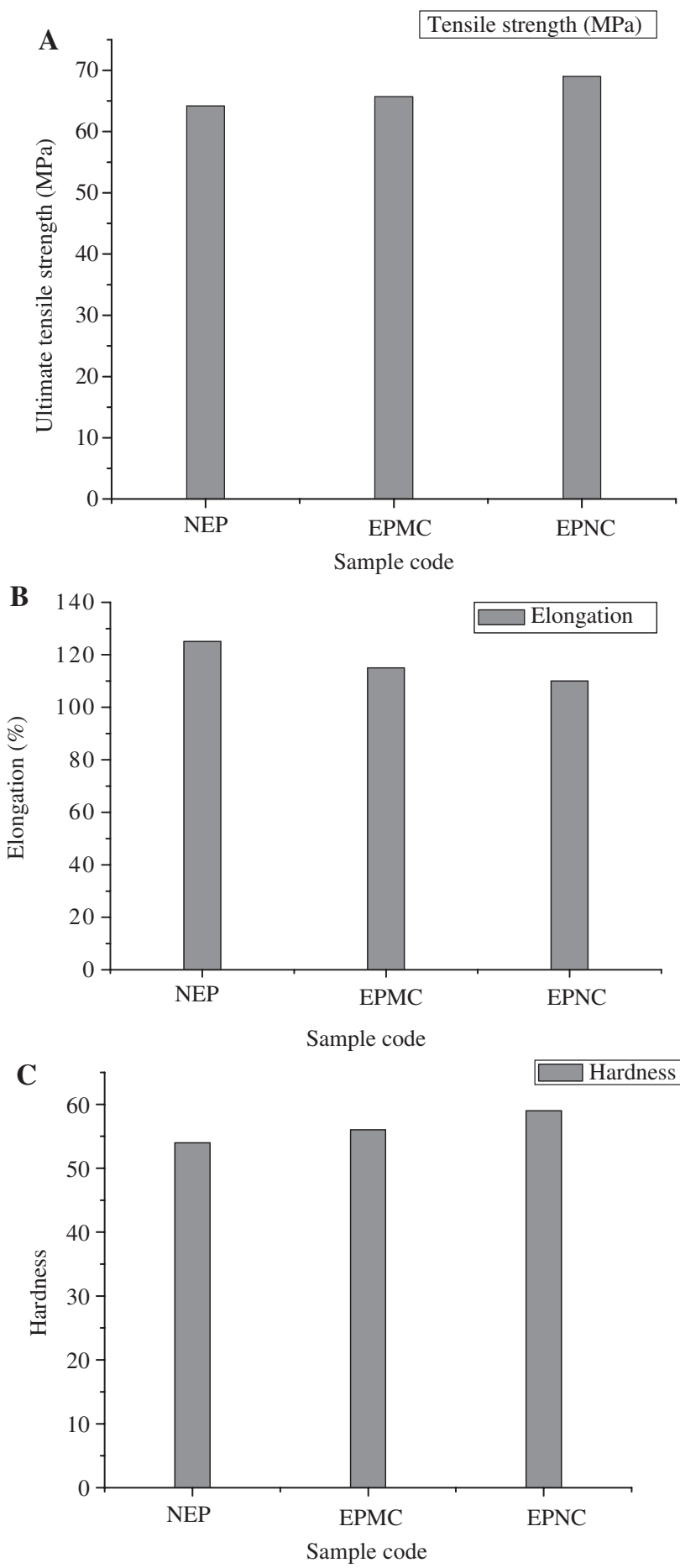

Figure 3: Mechanical properties of neat epoxy and epoxy composites: (A) tensile modules of neat epoxy and its nanocomposites and microcomposites; (B) percentage of elongation of neat epoxy and its nanocomposites and microcomposites; $(C)$ hardness of neat epoxy and its nanocomposites and microcomposites.

and hence gave the highest value of $209^{\circ} \mathrm{C}$ for a $10 \%$ loss in weight. EPMC and NEP showed 10\% weight losses at $185^{\circ} \mathrm{C}$ and $180^{\circ} \mathrm{C}$. Similarly, temperatures at $50 \%$ weight 

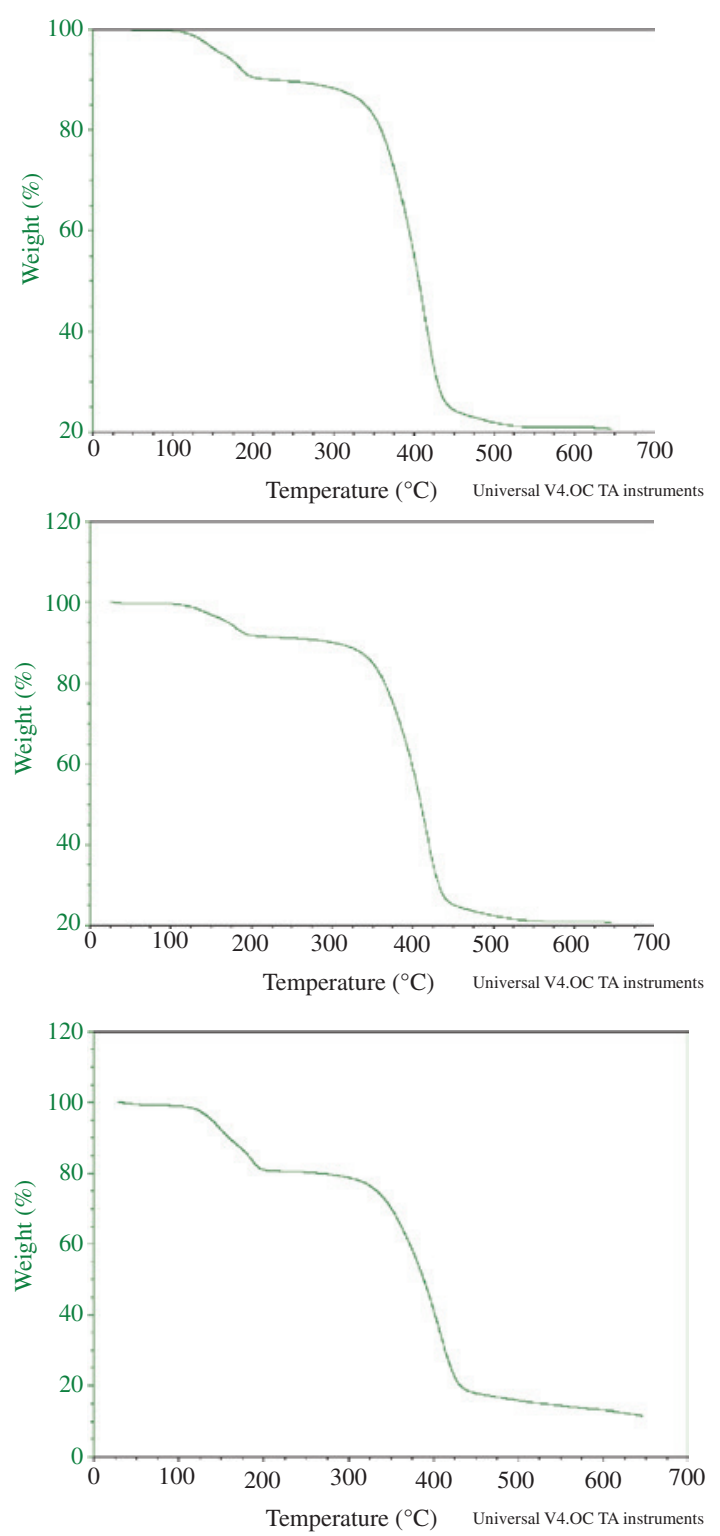

Figure 4: Thermograms of neat epoxy and epoxy composites: (A) thermogram of EPNC; (B) thermogram of EPMC; and (C) thermogram of NEP.

Table 2: Thermal properties of NE, EPMC, and EPNC.

\begin{tabular}{lrrr}
\hline Sample & $\boldsymbol{T}_{\mathbf{1 0}}\left({ }^{\circ} \mathrm{C}\right)$ & $\boldsymbol{T}_{\mathbf{5 0}}\left({ }^{\circ} \mathrm{C}\right)$ & \% Char yield \\
\hline NEP & 180 & 392 & 4 \\
EPMC & 185 & 410 & 9.5 \\
EPNC & 209 & 421 & 13 \\
\hline
\end{tabular}

loss $\left(T_{50}\right)$ for EPNC, EPMC, and NEP were $421^{\circ} \mathrm{C}, 410^{\circ} \mathrm{C}$, and $392^{\circ} \mathrm{C}$, respectively. Not only $T_{50}$ and $T_{10}$ but the percentage of char yield clearly showed that silica imparts thermal stability in epoxy, which is slightly greater in the case of nanocomposites. The polymer decomposition temperature also increased in the case of both composites. Enhanced thermal stability in composites is due to the very high glass transition temperature of silica. Furthermore, in nanocomposites, high thermally stability in comparison to microsilica is due to the better interaction of nanosilica by having a large polymer/particle interface area [41].

\subsection{Electrical properties}

The addition of silica contributed to the increase in dielectric strength, which was the highest in the case of nanocomposites. This behavior is credited to the better interaction of nanofillers within the matrix and the increased surface area of the nanofillers, which provides a strong polymer-filler network. For neat epoxy, a dielectric strength of $32 \mathrm{Kv} / \mathrm{mm}$ was recorded. An increase of $8 \%$ in dielectric strength was observed in the case of microcomposites. The nanocomposite showed a dielectric strength $38.2 \mathrm{kV} / \mathrm{mm}$, which was the highest and almost 1.2 times (19\%) greater than neat epoxy. The dielectric strengths of all samples are shown in Figure 5A-C.

Results for surface and volume resistivity are shown in Figure 5. The EPNC followed the same trend of superior properties. This improvement may be due to the smaller interspacing distance between filler particles and the intactness of the polymer matrix. Furthermore, due to the high resistivity of silica, the overall resistivity of the matrix increased. Surface resistivity of epoxy nanocomposite showed a similar increasing trend. This trend of surface resistivity is shown in Figure 5B. This could be due to the intercalation of nanofillers into the rubber matrix. Because the silica had insulating properties, it also imparted an increasing effect on the surface resistivity of epoxy composites. Furthermore, the same reasons behind the improved characteristics of nanocomposites in comparison to microcomposites, as explained by Nelson and $\mathrm{Hu}$ [41], were also stated in [37] for improved electrical characteristics.

\section{Conclusions}

Epoxy/silica nanocomposites and microcomposites were prepared and investigated for thermal, mechanical, and electrical characteristics. The influence of silica was observed in almost all the properties. In TGA, microsilica did not show significant enhancements in the properties 
A
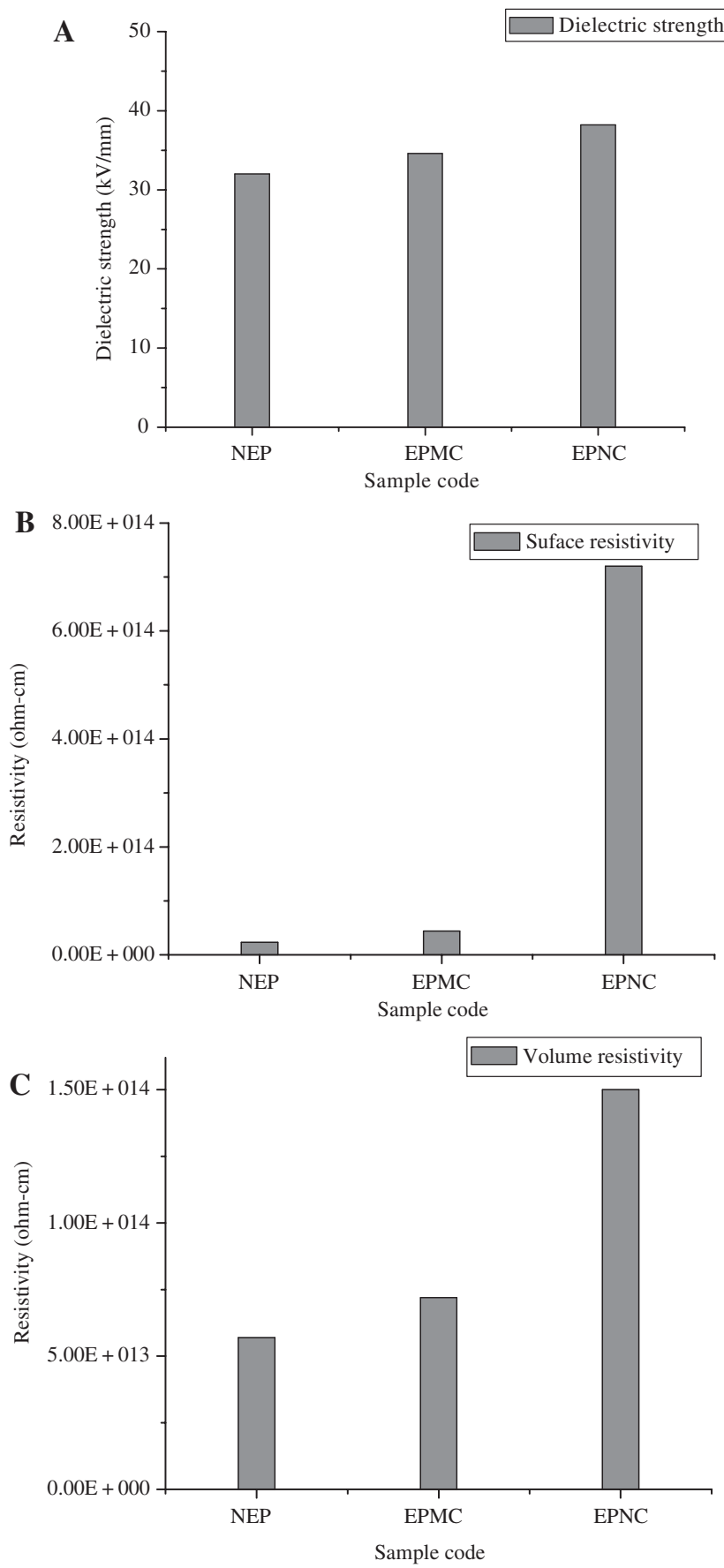

Figure 5: (A) Dielectric strength of NEP, EPMC, and EPNC; (B) surface resistivity of NEP, EPMC, and EPNC; (C) volume resistivity of NEP, EPMC, and EPNC.

of epoxy. The tensile strength and hardness of epoxy also showed little increases with the addition of $20 \%$ microsilica. Tensile strength and hardness increased to 65.3 Mpa and 3.7\% in EPMC, respectively. A decrease of $8 \%$ in elongation was recorded in EPMC. However, nanosilica at 5\% loading was found to be more prominent in enhancements of these properties. During TGA, the EPNC showed $10 \%$ less loss in weight in comparison to other samples. The dielectric strength of EPNC was increased by 1.2 times with the addition of nanosilica. Similarly, surface and volume resistivity were also enhanced by three and seven times, respectively. Tensile strength of EPNC also increased to 69.3 Mpa with an increase of $9.4 \%$ in hardness. Consequently, nanosilica is recommended for use in epoxy insulators.

\section{References}

[1] Schneider HM, Hall JF, Karady G, Renowned J. IEEE Trans. Power Deliv. 1989, 4, 2214-2221.

[2] Smith JDB, Schoch KF Jr., Su W-FA. Electrical insulation using liquid crystal thermoset epoxy resins. U.S. Patent 5904984 , issued May 18, 1999.

[3] Janssen H, Seifert JM, Karner HC. IEEE Trans. Dielectr. Electr. Insul. 1999, 6, 651-659.

[4] Sundhar S, Bernstorf A, Goch W, Linson D, Huntsman L. Polymer insulating materials and insulators for high voltage outdoor applications. In Conference Record of the 1992 IEEE International Symposium on Electrical Insulation. IEEE, 1992, pp. 222-228.

[5] Hackam R. IEEE Trans. Dielectr. Electr. Insul. 1999, 6, 557-585.

[6] An Z, Yin Q, Xiao H, Xie D, Zheng F, Lei Q, Zhang Y. IEEE Trans. Dielectr. Electr. Insul. 2015, 22, 1124-1133.

[7] An Z, Yin Q, Liu Y, Zheng F, Lei Q, Zhang Y. IEEE Trans. Dielectr. Electr. Insul. 2015, 22, 526-534.

[8] Luo B, Wang X, Zhao Q, Li L. Compos. Sci. Technol. 2015, 112, $1-7$.

[9] Khattak A, Amin M. J. Polym. Eng. 2015, 36, 199-209.

[10] Dang Z-M, Lin Y-H. Nan C-W. Adv. Mater. 2003, 15, 1625-1629.

[11] Kymakis E, Alexandou I, Amaratunga GAJ. Synth. Met. 2002, 127, 59-62.

[12] Marchi S, Sangermano M, Meier P, Kornmann X. Polym. Compos. $2014,35,1253-1262$.

[13] Vaisakh SS, Hassanzadeh M, Metz R, Ramakrishnan S, Chappelle D, Sudha JD, Ananthakumar S. Polym. Adv. Technol. 2014, 25, 240-248.

[14] Tjong SC. J. Nanosci. Nanotechnol. 2014, 14, 1154-1168.

[15] Singha S, Thomas MJ. IEEE Trans. Dielectr. Electr. Insul. 2008, 15, 12-23.

[16] Iyer G, Gorur RS, Richert R, Krivda A, Schmidt LE. IEEE Trans. Dielectr. Electr. Insul. 2011, 18, 659-666.

[17] Tanaka T. IEEE Trans. Dielectr. Electr. Insul. 2005, 12, 914-928.

[18] Gardea F, Lagoudas DC. Compos. Part B Eng. 2014, 56, 611-620.

[19] Chisholm N, Mahfuz H, Rangari VK, Ashfaq A, Jeelani S. Compos. Struct. 2005, 67, 115-124.

[20] Zhou Y, Pervin F, Lewis L, Jeelani S. Mater. Sci. Eng. A 2007, 452, 657-664.

[21] Dutta NK, Tripathy DK. J. Appl. Polym. Sci. 1992, 44, 1635-1648.

[22] Sun Y, Bao H-D, Guo Z-X, Yu J. Macromolecules 2008, 42, 459-463.

[23] Meyer LH, Cherney EA, Jayaram SH. IEEE Electr. Insul. Mag. 2004, 20, 13-21. 
[24] Kong SM, Mariatti M, Busfield JJC. J. Reinf. Plast. Compos. 2011, 30, 1087-1096.

[25] Tang LC, Wan YJ, Yan D, Pei YB, Zhao L, Li YB, Lai GQ. Carbon 2013, 60, 16-27.

[26] Jawaid M, Khalil HA, Hassan A, Dungani R, Hadiyane A. Compos. Part B Eng. 2013, 45, 619-624.

[27] Wan, YJ, Gong LX, Tang LC, Wu LB, Jiang JX. Compos. Part A Appl. Sci. Manuf. 2014, 64, 79-89.

[28] Chatterjee S, Wang JW, Kuo WS, Tai NH, Salzmann C, Li WL, Chu BTT. Chem. Phys. Lett. 2012, 531, 6-10.

[29] Corcione CE, Maffezzoli A. Polym. Test. 2013, 32, 880-888.

[30] Jin FL, Park SJ. Polym. Degrad. Stab. 2012, 97, 2148-2153.

[31] Tang LC, Wan YJ, Peng K, Pei YB, Wu LB, Chen LM, Lai GQ. Compos. Part A Appl. Sci. Manuf. 2013, 45, 95-101.

[32] Rajhan NH, Rozaina I, Hanizah AH, Azmi I. Influence of different fillers on the tensile properties of 50/50 NR/NBR blend. In InCIEC 2014, Springer, Singapore, 2015, pp. 767-777.

[33] Norshamira A, Mariatti M. Dielectric properties of inorganic fillers filled epoxy thin film. In Proceedings of the 23rd Scientific Conference of Microscopy Society Malaysia (SCMSM 2014), 2015, vol. 1669, p. 020021. AIP Publishing.

[34] Valášek P, Müller M. Agron. Res. 2014, 12, 291-298.

[35] Momen G, Farzaneh M. Rev. Adv. Mater. Sci. 2011, 27, 1-13.
[36] Tang D, Su J, Yang Q, Kong M, Zhao Z, Huang Y, Liao X, Liu Y. RSC Adv. 2015, 5, 55170-55178.

[37] Hu Y, Smith RC, Nelson JK, Schadler LS. Some mechanistic understanding of the impulse strength of nanocomposites. IEEE Conference on Electrical Insulation and Dielectric Phenomena (CEIDP), 2006.

[38] Imai T, Sawa F, Ozaki T, Inoue Y, Shimizu T, Tanaka T. Comparison of insulation breakdown properties of epoxy nanocomposites under homogeneous and divergent electric fields. IEEE Conference on Electrical Insulation and Dielectric Phenomena (CEIDP), 2006.

[39] Amin M, Ali M. Rev. Adv. Mater. Sci. 2015, 40, 276-294.

[40] Chang BP, Akil HM, Nasir RBM. Wear 2013, 297, 1120-1127.

[41] Nelson JK, Hu Y. The impact of nanocomposite formulations on electrical voltage endurance. In ICSD 2004. Proceedings of the 2004 IEEE International Conference on Solid Dielectrics, 2004, 2, 832-835.

[42] Zhang H, Ren T, Ji Y, Han L, Wu Y, Song H, Ba X. ACS Appl. Mater. Interfaces, 2015, 7, 23805-23811.

[43] Zhang H, Zhu X, Wu Y, Song H, Ba X. J. Mater. Sci. 2015, 50, 4387-4395.

[44] Amin M, Khattak A, Ali M. Micro Nano Lett. 2016, 11, 765-768.

[45] Ali M, Choudhry MA. Mater. Sci.-Poland 2015, 33, 213-219. 